\title{
0 perspectivismo na metafísica leibniziana
}

\author{
Celi Hirata (USP) \\ Orientador: Franklin Leopoldo e Silva \\ Bolsista da FAPESP
}

Em os Princípios da Natureza e da Graça, Leibniz deriva a proposição de que cada mônada representa todo o universo sob determinada perspectiva de duas premissas: uma física, conforme o mecanicismo dos modernos, e a outra metafísica. Por um lado, podemos inferi-la da plenitude do universo: uma vez que no mundo tudo está pleno de seres, sem qualquer vazio de alguma espécie, tudo está ligado no universo e todos os corpos agem sobre todos os outros de maneira proporcional às distâncias que eles mantém entre si. Conseqüentemente, cada substância espelha todo o universo, representando-o com mais distinção nas regiões mais próximas ao seu corpo. ${ }^{1}$

Por outro lado, as mônadas não possuem janelas, ${ }^{2}$ isto é, uma vez que em toda proposição verdadeira o predicado deve estar contido na noção do sujeito, tudo o que lhe ocorre deve provir dela mesma na forma de um predicado que se explicita. Assim, a influência de uma substância sobre outra só pode ser ideal, pois as percepções das

1 Príncipes de la Nature et de la Grâce, \$3 in Principes de la Nature et de la Grâce, Monadologie et autres textes (1703-1716). Paris: Garnier-Flammarion, 1996.

2 Lelbniz. Monadologia $\$ 7$ in Newton/ Leibniz. Coleção Os Pensadores, v. 17, São Paulo: Abril, 1983. 
mônadas possuem uma origem exclusivamente interna. Entretanto, há um acordo entre as mônadas. Isto porque Deus age perseguindo o máximo de conveniência nas coisas, acomodando todas as substâncias entre si, o que faz com que as percepçōes de cada mônada expressem todas as demais.

O perspectivismo é resultado do princípio do melhor, pois através dele é possível conciliar o máximo de efeitos, com a maior ordem possível. Este fato de que cada mônada expressa diferentemente das demais o universo inteiro só pode ser compreendido se submetido à criação divina - o ser perfeitíssimo, ao fazer a combinatória que resultaria no mundo, procurou a maior diversidade sem descurar da unidade que garante a ordem no universo. Desta forma, Deus "observando todos os aspectos do mundo de todas as formas possíveis (porque não existe nenhuma relação que escape à sua onisciência), faz com que o resultado de cada visão do universo, enquanto contemplado de certa maneira, seja uma substância expressando esse relance" . 3 Conseqüentemente, um mesmo e único universo é multiplicado pelos infinitos pontos de vista existentes, o que é próprio da sabedoria divina. Enfim, a proposição de que cada substância representaria todo o universo à sua maneira estaria justificada metafisicamente: o perspectivismo é necessário não somente porque é próprio da natureza das substâncias, individualizando-as, ${ }^{4}$ mas também porque é digno da sabedoria divina.

Entretanto, se tanto física mecanicista quanto metafísica são evocadas para dar sustentação à sentença de que cada mônada é um

3 LeIBNIz. Discurso de Metafísica, proposição 14 in Newton/ Leibniz. Coleção Os Pensadores, v. 17. São Paulo: Abril, 1983.

4 "Se as substâncias simples em nada diferissem pelas suas qualidades, não haveria meio de se aperceber qualquer modificação nas coisas, pois o que está nos compostos não pode vir senão dos ingredientes simples e as Mônadas seriam indistinguíveis umas das outras"( $\$ 8 \mathrm{da}$ Monadologia). "É mesmo preciso todas as Mônadas diferirem entre si, porque na Natureza nunca há dois seres perfeitamente idênticos" (§9), "E é apenas isso, precisamente, o que se pode encontrar na substância simples: percepções e suas modificações." (\$17) Ora, uma vez que 
espelho vivo do universo inteiro sob uma determinada perspectiva, há, no entanto, uma diferença muito grande entre os dois ramos de conhecimento mencionados. Enquanto a metafísica trata de maneira rigorosa questões como esta, o mecanicismo as conduz para um outro plano - o fenomênico. Por esta abordagem, o perspectivismo só pode ser pensado em termos de aparência.

Rigorosamente, onde não há um ser, não há um ser. ${ }^{5}$ Assim, as substâncias individuais são as verdadeiras constituintes da realidade, elas são "os Elementos das coisas" " É delas que provém tudo quanto se sucede no mundo. Isto porque"toda predicação tem algum fundamento verdadeiro na natureza das coisas", 7 e, conseqüentemente, tudo o que ocorre deve ser atribuído às noçōes individuais de cada mônada. Os fenômenos só podem se dar, portanto, na medida em que se fundamentam nas naturezas substanciais, sendo que eles mesmos não possuem uma realidade absoluta, mas apenas derivada: são aparências que resultam de predicados substanciais, possuindo eles alguma realidade apenas na medida em que se reportam a estes.

Daí ser limitada a dedução mecanicista do ponto de vista inerente às mônadas - literalmente, o perspectivismo não pode resultar de uma influência mecânica entre os corpos, pois, como Leibniz repete diversas vezes, as substâncias não possuem janelas. Assim, a plenitude do universo não pode operar como princípio explicativo último do perspectivismo, mas só pode ser compreendida como uma maneira de reforçar a dedução em outra ordem, respeitando a dupla via de

as mônadas consistem nas suas percepções e dado que todas elas possuem o mesmo conteúdo perceptivo (o universo inteiro), a diferenciação que se dá entre elas só pode provir das perspectivas inerente às expressões de cada uma, do modo como elas representam o mesmo mundo. Elas individualizam-se, portanto, pelos respectivos pontos de vista.

5 A natureza própria da verdade, pela qual todo predicado deve poder ser reportado a um sujeito, exige que haja substâncias simples, isto é, sem partes.

6 Monadologia, § 3.

7 proposição 8 do Discurso de Metafísica. 
explicação que o autor tem por costume utilizar - a via mecanicista e a via metafísica. Tomada rigorosamente, a perspectiva de cada mônada considerada como ponto de vista espacialmente situado traria problemas de compreensão, tais como a difícil conciliação que haveria com a consideração de que os espíritos também seriam, além de espelhos do universo, espelhos de Deus, o qual, por sua vez, se encontra fora do espaço e do tempo. ${ }^{8}$

O mesmo parece ocorrer com outra formulação que Leibniz utiliza ao tratar do perspectivismo. Ele a expõe deste modo: "toute substance est comme um monde entier et comme um mirroir de Dieu ou bien de toute l'univers, qu'elle exprime chacune à sa façon, à peu près comme une même ville est diversement représenteé selon lês differentes situations de celui qui la regarde." "Assim, quando o filósofo expõe o ponto de vista por uma analogia com as diferentes representações que uma cidade possui segundo a situação daqueles que a observam, ele está servindo-se de uma metáfora que não pode ser empregada de modo absoluto. É importante notar que o próprio Leibniz faz questão de demarcar o sentido figurado da imagem, demarcação que é bem salientada pelo uso da expressão "à peu près"

Ora, como cada substância deve conter em si mesma, na forma de predicados, tudo o que lhe sucede, parece ser vital para a compreensão do perspectivismo a assinalação do território ao qual pertence: o metafísico. Com efeito, se cada mônada reflete o universo inteiro sob determinado ponto de vista, se cada uma expressa de maneira tão

8 Com efeito, se cada mônada possui um ponto de vista espacialmente situado, espelhando o universo inteiro, porém com mais distinção em relação aos corpos próximos ao seu, como os espíritos poderiam espelhar também Deus, que se encontra fora do espaço e do tempo? Parece que há uma certa incompatibilidade se ambas as afirmações são tomadas ao pé da letra: como o espírito, cujas percepçōes se reportam a uma perspectiva espacial e temporalmente situada, poderia alcançar as verdades eternas e necessárias? Com efeito, este é um problema que me limito a apontar, sem desenvolvê-lo.

9 Discurso de Metafísica, proposição 9. 
regrada quanto a do universo toda a seqüência das ocorrências exteriores a ela, se, enfim, cada substância exprime, mesmo que confusamente, um conteúdo infinito, envolvendo não só o presente, como o passado e o futuro, é porque tudo isto é próprio de sua natureza. Por um lado, considerando-se o preceito de que em toda proposição verdadeira o predicado deve estar contido na noção do sujeito, a própria mônada deve ser a fonte de suas percepções. Por outro, pelo princípio de identidade dos indiscerníveis, não há nunca dois seres iguais no. universo, e, portanto, duas substâncias não poderiam expressar da mesma forma: se, de um lado, todas encerram o mesmo conteúdo, elas o expressam, contudo, de modos diferentes, encadeando os acontecimentos do mundo de maneira peculiar que as distinguem das demais.

É também através do princípio de identidade dos indiscerníveis que a questão do perspectivismo é reconduzida ao plano metafísico pensado do ponto de vista da criação. Este princípio, com efeito, ligase intimamente ao de razão suficiente e ao do melhor: como tudo o que existe é fruto da escolha divina, não haveria razão para que dois seres reais e indiscerníveis encontrassem-se no universo, pois se tal ocorresse não haveria motivo para Deus escolher um de preferência a outro. Ou seja, dois seres ou duas situações existentes e absolutamente semelhantes infringiriam o princípio de razão suficiente, pois, neste caso, a escolha divina recairia na indiferença. $O$ mundo criado é resultado da combinatória divina que, submetida à sua sabedoria, aparece como concretização do melhor. Neste contexto, o perspectivismo aparece como via pela qual o máximo de variedade é conciliada com o máximo de ordem: "c'est comme si Dieu avait varié l'univers autant de fois qu'il y a d'âmes, ou comme s'il avait crée autant d'univers en raccourci convenants dans le fond, et diversiée par les apparences."10 Ou seja, ao mesmo tempo que a copiosidade é efetivada pelos infini-

${ }^{10}$ LeIBNiz. Lettre à la Reine Sophie-Charlotte in Principes de la Nature et de la Grâce, Monadologie et autres textes (1703-1716). Paris: Garnier-Flammarion, 1996. 
tos pontos de vista, a unidade é garantida porque todas expressam o mesmo conteúdo, isto é, remetem a um mesmo universo. Todos os seres criados, com as suas respectivas percepções, concordam entre si, pois representam o mesmo mundo. E, no entanto, as substâncias diferenciam-se essencialmente uma das outras por suas representações, pelas perspectivas que lhes são próprias. Assim, o fato de que cada mônada expressa todo o universo de um determinado modo que lhe é particular mostra-se resultado do princípio de conveniência, pelo qual Deus cria o melhor dos mundos possíveis.

Enfim, o perspectivismo parece ser apenas adequadamente compreendido na esfera da metafísica. Se por um lado Leibniz evoca para o tratamento da questão as duas vias de explicação - a mecânica ou eficiente e a finalista - ele mesmo parece atribuir uma certa superioridade epistemológica à segunda quando se trata de questões mais gerais e fundamentais como esta. ${ }^{11} \mathrm{O}$ perspectivismo diz respeito à própria essência da mônada, sendo, portanto, anterior aos fenômenos. Isto é: na medida em que faz parte da natureza das substâncias criadas, o perspectivismo não está no plano fenomênico. Além disso, ele só adquire pleno sentido quando entendido como parte dos desígnios divinos, ou, o que é o mesmo, como conseqüência do princípio do melhor - um dos principais preceitos metafísicos de Leibniz.

${ }^{11}$ Se por um lado, a causalidade eficiente é a mais adequada para a explicitação dos fenômenos particulares, por outro ela é insuficiente quando se trata de questões mais gerais. Ora, as séries causais são infinitas e nunca chegam ao término, sendo incapazes de fornecer um fundamento por elas mesmas. 